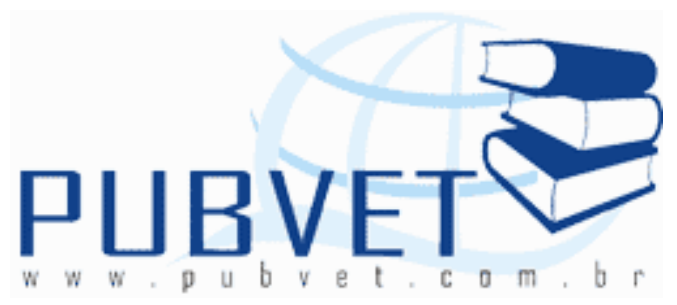

PUBVET, Publicações em Medicina Veterinária e Zootecnia.

https://doi.org/10.31533/pubvet.v02n12a460.1-6

\title{
Qualidade de cortes da carcaça ovina, bovina, suína e aves
}

Christian Albert Carvalho da Cruz $^{1}$, Alexilda Oliveira de Souza ${ }^{2}$, Cristiane Leal dos Santos-Cruz ${ }^{3}$

${ }^{1}$ Mestrando em Engenharia de Alimentos.

${ }^{2}$ Prof. a DSc. do DEBI - UESB.

${ }^{3}$ Prof.a DSC. do DTRA - UESB.

\section{Resumo}

Objetivou-se determinar a composição centesimal de diferentes cortes da carcaça, sendo 03 (três) filés de peito de frango, 03 (três) patinhos de ovino, 03 (três) contra-filés bovino e 03 (três) picanhas suína. A porção comestível do contra-filé bovino foi a que apresentou maior teor de gordura total, enquanto que o filé de peito de frango apresentou maior teor de proteína. A atividade de água nos cortes foi semelhante, com destaque para a carne ovina, a carne de frango apresentou maior luminosidade e com tendência para o tom amarelo, enquanto a carne bovina apresentou os tons mais vermelhos.

Palavras-chave: carne, composição, química.

Quality of cuts of the carcass sheep, cattle, swine and chicken 


\section{Abstract}

The objective was determined the centesimal composition de different cuts of the carcass, 03 (three) chicken filets of chest, 03 (three) sheep cap of rump, 03 (three) bovine striploin and 03 (three) swine cover of rump. The eatable portion of the bovine striploin was the one that it presented larger tenor of total fat, while the filet of chicken chest was the more protein. The activity of water in the cuts was similar, with prominence just for the meat sheep, the chicken meat was already the most luminous and with tendency to the yellow tone, while the bovine presented redder tones.

Keywords: meat, composition, chemical.

\section{INTRODUÇÃO}

A determinação da composição corporal deve ser entendida como a análise física e/ou química, direta, de todos os tecidos do animal, ou seja, consequentemente da carcaça e carne que compõem o corpo. Sendo assim, o conhecimento da composição centesimal da carne em porcentagem de água, proteína, gordura e cinzas são de grande interesse na comparação de grupos genéticos, raças e espécies. De acordo com FEKETE e BROWN (1992), variações na composição corporal (carcaça e carne) de animais, bem como suas carcaças, podem ser afetadas tanto por fatores endógenos (raça, sexo, idade, peso ou estado fisiológico) como exógenos (jejum, nível de ingestão, ingredientes da ração, fibra dietética e relação de proteína energia).

\section{MATERIAL E MÉTODOS}


O experimento foi desenvolvido no Laboratório de Análise Química da Unidade Experimental de Caprinos e Ovinos - UECO, da Universidade Estadual do Sudoeste da Bahia-Uesb, campus de Itapetinga-Ba. Foram utilizados os seguintes cortes da carcaça: 03 (três) filés de peito de frango, 03 (três) patinhos de ovino, 03 (três) contra-filés bovino e 03 (três) picanhas suína, obtidos no Supermercado Hiper Bom Preço, com exceção dos cortes ovinos que foram obtidos na UECO. Estes cortes foram dissecados para obtenção da porção comestível (músculo e gordura), que após moagem foram obtidas triplicatas e/ou amostras de cada corte para análise química, ou seja, foram realizadas análises em 09 amostras ou triplicatas de cada corte, totalizando 27 amostras.

Como os cortes foram obtidos em locais comerciais, exceto o patinho ovino, não foi possível obter informações para caracterização completa do produto, como a idade de abate, tipo de dieta que fornecida, raça, sexo, local de criação e outros fatores endógenos e exógenos considerados importantes. Sendo assim, considerou-se para efeitos de comparação a espécie, ressaltando-se que o interesse era conhecer os aspectos químicos de produtos de não rastreados, visto que produtos com pouca informação no rótulo vêm sendo consumidos.

O delineamento foi inteiramente casualizado com 03 repetições de cada triplicata de cada corte, ou seja, 09 repetições por corte. O percentual de umidade foi determinado através de uma balança determinadora de umidade por infravermelho a $175^{\circ} \mathrm{C}$ pó 20 minutos. O teor de minerais foi obtido da queima a $600^{\circ} \mathrm{C}$ por 6 horas. A proteína através do método de macro Kjedhal com $2 \mathrm{~g}$ de amostra. A gordura ou lipídios totais foi obtido segundo metodologia de SANTOS (2002) adaptado de SILVA (2002). Dentre os parâmetros de qualidade foram analisados a atividade de água, por meio do aqualab e cor das carnes, por meio de um colorimetro ColoquestXE Huterlab, em que $L^{*}$ - varia do branco (100) ao preto (0), a* - transição da cor verde 
$\left(-a^{*}\right)$ para a cor vermelha (+a*) e $\quad b^{*}$ - transição da cor azul (-b*) para a cor amarela $\left(+b^{*}\right)$.

Para comparar os tipos de carne quanto à composição centesimal foi realizada a análise estatística pelo Programa SAS (2000) e utilizou-se o teste de Tukey (5\%).

\section{RESULTADOS E DISCUSSÃO}

A composição centesimal, em valores percentuais de umidade, lipídios totais, minerais e proteína, filé de peito de frango, contra-filé bovino, patinho ovino e picanha suína são apresentados na Tabela 1, assim como seus valores calóricos.

Houve diferença significativa para o teor de umidade dos cortes analisados, ou seja, o filé de peito de frango apresentou maior teor de umidade $(73,00 \%)$ em relação à carne bovina $(70,00 \%)$, ovina $(69,00 \%)$ e suína $(70,00 \%)$. O teor de umidade está diretamente correlacionado aos teores de proteína e inversamente ao de gordura, podendo a quantidade de água pode variar de músculo para músculo dentro de espécies, mas geralmente esta variação é pequena, como, por exemplo, entre cabras e cordeiros. Em geral, os animais jovens apresentam maior teor de água, considerando este aspecto poderíamos afirmar que o filé de peito de frango advém de animais jovens, mas isso seria errôneo por não considerar a influência de outros fatores, dentre eles o tipo de corte da carcaça, pois diferentes partes do corpo se desenvolvem de forma diferente depositando assim nutrientes nos tecidos de forma também diferente. MATTOS et al (1997) ao avaliarem a carne de bovinos Nelore encontraram valores de $23,3 \%$ PB (superior ao deste trabalho).

A atividade de água nos cortes foi semelhante, com destaque apenas para a carne ovina que apresentou atividade de 0,991 aw, no entanto em relação à cor, a carne de frango foi a mais luminosa $(61,05)$ o que está diretamente relacionado o índice " $\mathrm{b}$ " que também o maior, sendo 14,78 , ou 
Cruz, C.A.C., Souza, A.O. e Cruz, C.L.S. Qualidade de cortes da carcaça ovina, bovina, suína e aves. PUBVET, Londrina, V. 2, N. 48, Art\#460, Dez1, 2008.

seja uma carne mais clara e com tendência ao tom amarelo, enquanto que a bovina apresentou tons mais avermelhados, sendo o valor médio de "a" de 10,55. Os valores médios da atividade de água e cor de cortes da carcaça de são apresentados na Tabela 2.

\section{CONCLUSÕES}

A porção comestível do contra-filé bovino foi a que apresentou maior teor de lipídeos totais, enquanto que o filé de peito de frango foi o mais protéico. A atividade de água nos cortes foi semelhante, com destaque apenas para a carne ovina, já a carne de frango foi a mais luminosa e com tendência ao tom amarelo, enquanto que a bovina apresentou tons mais avermelhados.

\section{REFERÊNCIAS BIBLIOGRÁFICAS}

1. FEKETE,S.; BROWN, D.L. Prediction of body composition in rabbits by deuterium oxide dilution and total body electrical conductive with validation by diret chemical analysis. Journal Applied Rabbit Research, Lempeds, v.15, p. 787-798., 1992.

2. MATTOS, J.C.A.; NOGUEIRA, J.R.; OLIVEIRA, A.A.D. et al. Comparison on carcass, meat cuts and some meat quality characteristics of buffaloes and zebu. In: WORLD BUfFALOCONGRESS, 5., Caserta, 1997. Proceedings... Caserta: FAO/IBF, 1997. p.442-446.

3. SANTOS, C.L. Estudo do Crescimento e da Composição Química dos Cortes da Carcaça de Cordeiros Santa Inês e Bergamácia. Lavras: Universidade Federal de Lavras: UFLA- MG, 2002, 147p. (Doutorado - Tese em Produção Animal)

4. SILVA, D. J.; QUEIROZ,A.C. Análise de Alimentos: Métodos Químicos e Biológicos. 3a ed. Viçosa:UFV. 2002. 235p.

5. SAS INSTITUTE Inc. SAS/ETS ${ }^{\circledR}$ User's guide. Version 6. 2. ed. Carolina:Cray:SAS Institute Inc., 2000. 
TABELA 1. VALORES MÉdios da COMPOSIÇÃo CENTESimal de CORTES DA CARCAÇA DE DIFERENTES ESPÉCIES ANIMAIS.

\section{Composição centesimal}

\begin{tabular}{|c|c|c|c|c|c|c|}
\hline \multirow[b]{2}{*}{ Espécie } & \multirow[b]{2}{*}{ Corte } & & & & & \\
\hline & & $\begin{array}{c}\text { Umidade } \\
(\%)\end{array}$ & $\begin{array}{c}\text { Lipídeos } \\
\text { Totais } \\
(\%)\end{array}$ & $\begin{array}{c}\text { Minerais } \\
(\%)\end{array}$ & $\begin{array}{c}\text { Proteína } \\
(\%)\end{array}$ & $\begin{array}{c}\text { Valor } \\
\text { Calórico } \\
\text { (Kcal) }\end{array}$ \\
\hline Frango & $\begin{array}{c}\text { Filé de } \\
\text { Peito }\end{array}$ & $73,00 \mathrm{a}$ & $0,793 \mathrm{~b}$ & $0,978 a b$ & $15,51 \mathrm{a}$ & $0,077 \mathrm{c}$ \\
\hline Bovino & $\begin{array}{c}\text { Contra- } \\
\text { filé }\end{array}$ & $70,00 \mathrm{~b}$ & $6,578 \mathrm{a}$ & $0,94 \mathrm{~b}$ & $12,68 a b$ & $0,68 a$ \\
\hline Ovino & Patinho & $69,00 \mathrm{~b}$ & $2,266 \mathrm{~b}$ & $1,03 a$ & $11,80 a b$ & $0,32 \mathrm{~b}$ \\
\hline Suíno & Picanha & $70,00 \mathrm{~b}$ & 4,777 a & $1,02 a b$ & $8,02 b$ & $0,62 a$ \\
\hline
\end{tabular}

tabela 2. Valores médios da atividade de Água e cor de CORTES DA CARCAÇA DE DIFERENTES ESPÉCIES ANIMAIS.

\begin{tabular}{cccccc}
\hline Espécie & Corte & $\begin{array}{c}\text { Atividade de } \\
\text { Água }\end{array}$ & L & a & b \\
& & $0,990 \mathrm{~b}$ & $61,057 \mathrm{a}$ & $3,510 \mathrm{a}$ & $14,783 \mathrm{a}$ \\
\hline Frango & Filé de Peito & $0,990 \mathrm{~b}$ & $38,837 \mathrm{ab}$ & $10,553 \mathrm{a}$ & $8,787 \mathrm{~d}$ \\
Bovino & Contra-filé & $0,991 \mathrm{a}$ & $38,107 \mathrm{~b}$ & $9,617 \mathrm{~b}$ & $10,517 \mathrm{c}$ \\
Ovino & Patinho & $0,990 \mathrm{~b}$ & $59,873 \mathrm{ab}$ & $5,653 \mathrm{c}$ & $13,607 \mathrm{~b}$ \\
Suíno & Picanha & 5 letra na coluna não são diferentes entre si de \\
\hline Médias seguidas de mesma & & & &
\end{tabular}

